\title{
Cunoaşterea prin Cuvânt în Tradiția Bibliei
}

\section{Lucian DABIJA}

Abstract: We always consider the speaking and the utterance like a special dimension of the human, but rarely we take a look on what Bible says about it. In St. John Prologue, we have a clear identity for the Word as The Second Person of The Holy Trinity. It is a peack of understanding and also point where all of the knowledge about The Logos can achieve the height.

Keywords: Logos and Davar, Moses Dialog with God, Word Theology.

\section{Cunoașterea prin Cuvânt în Vechiul Testament}

Preocuparea asupra temei cunoașterii prin cuvânt nu poate omite conținutul Revelației biblice și ceea ce s-a fundamentat mai apoi ca Tradiție. Vom parcurge succint câteva învățături statornice 


\section{Lucian DABIJA}

din Tradiție și momente ale Revelației ce pot susține o perspectivă unitară a modului în care Dumnezeu S-a făcut cunoscut oamenilor prin cuvânt.

În prezent, în limba ebraică cuvântul este pronunţat ca ,davar”, reprezentând în acelaşi timp un obiect sau un lucru. Vom vedea, prin exemple de citate biblice, că el este atât de vechi în semnificaţie cât şi în formă ca şi momentele biblice în care s-a evidenţiat. Limba ebraică nu a cunoscut vocalizare, ceea ce face rădăcina dalet vav reș (dvr) să fie cea din care se derivă cuvinte precum ,vorbire” (devarim) ${ }^{2}$, concluzie (aharit davar), în legătură cu (al davar)"’3 etc. Rădăcina cuvântului davar (dalet vav reș) este utilizată cu multe sensuri desemnând o multitudine de cuvinte. Ea apare în Vechiul Testament de ,1697 de ori, fiind sinonimă următoarelor cuvinte grecești: adikos, antilogia, apokrisis, biblion, ramma, grammateus, diatheke, dike, dolos, entole ergon, krima, krisis, lalia, logion, logos, nomos, pragma, stoma, tropos, phone, chrema, rhema"4. Dacă este să considerăm davar doar ca ,act de vorbire, în versiunea ebraică acesta se întâlnește de mai bine de 5200 de ori, adesea utilizat referindu-se la discuţia dintre două persoane, sau folosit ca substantiv"'.

Cuvântul este unitatea de bază și în semantică. Aceasta este un instrument pentru o înţelegere corectă a sensul cuvintelor. Iată, un exemplu în care semantica îl ajută pe Fericitul Augustin să respingă o interpretare eretică asupra textului de la Ioan 1,1-2: „Iar acum să vedem exemple: Acea frazare eretică: in pricipio erat Verbum, et

${ }^{1}$ Dr. Alfred Hârloianu, Dicţionar explicativ român-ebraic de la literele AlefLamed, ediţia a II-a, Bucureşti, Ed. Nemira, 2002, p. 67.

${ }^{2}$ Aici devarim nu este forma pluralului lui davar. Din această perspectivă, vorbirea presupune mai multe cuvinte.

${ }^{3}$ A. Hârloianu, op. cit., pp. 67-68.

${ }^{4}$ Număr generat automat de http://studybible.info/strongs/H1697 confrom Strongs Hebrew Lexicon (5.09.2015).

${ }^{5}$ NIB. The New Interpreters Dictionary of the Bible S-Z, ed. Katharine Doob, Sakenfeld, vol. 5, Nashville, Ed. Abington Press, 2009, p. 893. 
Verbum erat apud Deum, et Deus era («la început era Cuvântul, iar Cuvântul era la Dumnezeu, iar Dumnezeu era)», pentru ca sensul să fie altul: Verbum hoc erat in principo apud Deum («Cuvântul acesta era la început întru Dumnezeu»), nu vrea să recunoască Verbul ca Dumnezeu, or lucrul acesta este de respins prin regula de credință, care, în legătură cu egalitatea Treimii, ne prescrie să spunem et Deus erat Verbum («iar Dumnezeu era Cuvântul»), iar apoi să adăugăm hoc erat in principio apud Deum (In. 1,1-2; «acesta era la început întru Dumenzeu»)"'.

Fericitul Augustin recunoaşte dificultatea cu care texul biblic se poate aborda, remarcând în primul rând greșelile de utilizare pe care interpretul sau scribul le face. Prima tentație în interpretare este de a aborda cele mai taince momente ale Revelației interpretându-le cu ajutorul conceptelor, dar fără a insista pe semnificațiile ce reies din contextul sintactic sau din sensul comun al cuvintelor: „Dar atunci când Scriptura are ambiguități datorate unor cuvinte în sens propriu, este de observat mai întâi dacă nu am frazat sau nu am pronunțat greșit. Când deci se va fi observat că în ciuda atenției noastre, este neclar în ce mod trebuie să frazăm sau să pronunțăm, să se consulte regula de credință, pe care o dau pasajele mai clare ale Scripturii și autoritatea Bisericii, regulă despre care am vorbit îndeajuns în prima carte, când am tratat despre lucruri'”’

Cuvintele devin semne, pe care Sfânta Scriptură, datorită naturii lor volatile, le păstrează și protejează pentru lume. „Dar, fiindcă, după ce au pus în mișcare aerul, cuvintele se duc îndată și nu rămân mai mult decât se aud, au fost instituite prin litere, semne ale cuvintelor. În felul acesta cuvintele sunt arătate ochilor, nu prin ele însele, ci prin semne specifice lor. Or aceste semne nu au putut fi comune tuturor popoarelor, dintr-un păcat: acela al neînțelegerii între oameni, pentru

\footnotetext{
${ }^{6}$ Sf. Augustin, De doctrina christiana, trad. Marian Ciucă, București, Ed. Humanitas, 2002, p. 201.

${ }^{7}$ Ibidem, p. 199.
} 


\section{Lucian DABIJA}

fiecare se înstăpânește pe întâietate. Ca semn al acestei trufii a fost ridicat la cer acel turn în care oamenii și-au găsit plata necredinței lor: să fie diferiți nu numai la suflet, ci și după limbi (Facere 11, 1-9)"»8.

Până la Moise ni se prezintă crearea lumii prin Logos (Cuvânt) precum și dialogul lui Dumnezeu cu Adam: „După acestea, fost-a cuvântul Domnului către Avram, noaptea, în vis, și a zis: «Nu te teme, Avrame, că Eu sunt scutul tău si răsplata ta va fi foarte mare!» (Facere 15,1); Turnul Babel (Facere 11, 1-7), unde se afirmă și existența Celor Trei Persoane «Veniți pogorându-ne să amestecăm limba lor, ca să nu înțeleagă niciunul glasul aproapelui său»" (Facere 11,7). Din conţinutul Facerii, semnificațiile lingvistice prezintă o importanță majoră, deoarece nu dispunem de izvoare complementare de cunoaştere. În timp, această idee a derivat în ceea ce concluzionăm ca fiind sacralitatea unei limbi: „Ebraica poartă deci, ca niște rămășiţe, mărcile numirii primare. Și aceste cuvinte pe care Adam le-a pronunțat, impunându-le animalelor, s-au păstrat, cel puțin în parte, închizând în ele, în profunzimea lor, ca un fragment de știință tăcută, proprietățile imuabile ale fiinţelor"

Utilizarea pluralului pronominal și verbal este unul dintre marile indicii vechitestamentare prin care Dumnezeu S-a făcut cunoscut ca Treime. „Verbul la plural (cf. Gen. 1,26): după Philon, Dumnezeu deliberează în el însuși, apoi poruncește «puterilor» (Confus. 162168). După Origen (Com. Io. XIII, 50), Dumnezeu vorbește îngerilor iar după Vasile cel Mare, este o deliberare a Treimii (Adv. Eun V, 4). «Amestecăm», dar nu există decât o limbă: normal ar fi fost, aşa cum scrie și Philon (Confus. 183-195), ca Dumnezeu să despartă întâi limbile una de alta, pentru a le amesteca ulterior. Dar «amestecul» trimite aici la ideea pierderii de sens a cuvintelor, la ideea bruiajului

\footnotetext{
${ }^{8}$ Ibidem, p. 115.

${ }^{9}$ Biblia, București, Tipografia Cărților Bisericești, 1914.

${ }^{10}$ Foucault, Michel, Cuvintele și lucrurile, trad. Bogdan Ghiu și Mircea Vasilescu, București, Ed. Rao, 2008, p.93.
} 
fonic. Se trece de la homophonia inițială, paradisiacă, la heterophonia, diaphonia sau «poliphtongia» decăderii (cf. Iustin, ibid., 102,4)"”11.

Moise este părtașul unei cunoașterii mistice unice a Cuvântului lui Dumnezeu pe muntele Sinai. „În acest loc Moise este condus la o cunoaştere tainică, însăși puterea dumnezeiască învățând prin minuni mai presus de cuvânt tot poporul și pe însuși conducătorul lui""12.

Sf. Grigorie de Nyssa descrie glasul lui Dumnezeu astfel: „,ăci un glas de sus, izbucnind, se prăvălea peste toată suflarea, iar prima lui atingere era înfricoșătoare și de nesuportat pentru orice auz. Se asemăna cu sunetul trâmbițelor, dar întrecea prin tăria înfricoşătoare și înspăimântătoare a lui orice pildă. Iar glasul era articulat prin puterea dumnezeiască și nu prin organele vorbirii, însuși aerul articulând cuvântul. Iar cuvântul nu era articulat fără un scop, ci dădea ca legi învățăturile dumnezeiești. Și glasul înaintând sporea în tărie și sunetul trâmbițelor se întrecea pe el însuşi. Iar poporul întreg era copleșit, încât nu mai putea să suporte ceea ce se arăta și se auzea (Ieșire 19). De aceea el face o cerere de obște lui Moise, ca să-i mijlocească legea prin el. Căci poporul nu se va îndoi că tot ce se va vesti prin el, potrivit învățăturii de mai sus, e poruncă dumnezeiască"'13.

Dialogul lui Moise cu Dumnezeu de pe Muntele Sinai este comparat $\mathrm{cu}$ urcuşul în cunoașterea lui Dumnezeu. Moise 1-a cunoscut pe Dumnezeu pe Munte iar poporul neinițiat a rămas în necunoaștere și în frica de moarte. „Numai după ce s-a curățat astfel, să îndrăznească să se apropie de munte. Căci cu adevărat munte înălțat pieptiș și greu de urcat este cunoașterea de Dumnezeu (Teologia). Şi mulțimea poporului de-abia ajunge la poalele ei. Iar dacă este vreun

${ }^{11}$ Septuaginta, volum coordonat de Cristian Bădiliță, Francisca Băltăceanu, Monica Broșteanu, Dan Slușanschi în colaborare cu pr. Ioan-Florin Florescu, vol. 1, Colegiul Noua Europă, București, Ed. Polirom, 2004, p. 78.

${ }^{12}$ Sf. Grigorie de Nyssa, Despre viața lui Moise sau desăvârșirea prin virtute, Scrieri partea I, PSB, vol. 29, Trad. Dumitru Stăniloae și Pr. Ioan Buga, București, Ed. EIBMBOR, 1982, p. 31.

${ }^{13}$ Ibidem, pp. 31-32. 


\section{Lucian DABIJA}

Moise, acela poate să urce, primind în auz sunetul trâmbițelor, despre care spune cuvântul istorisirii că se aud tot mai tare pe măsura urcării. Iar trâmbița care lovește auzul este predica despre firea dumnezeiască și ea e puternică încă de la prima auzire, și lovește tot mai tare auzul celor ce au înaintat până la capăt....Iar mulțimea nu poate să cuprindă glasul ce vine de sus, dar lui Moise i se îngăduie să cunoască prin el cele negrăite, și apoi să învețe și pe popor poruncile pe care s-a învrednicit să le afle din învătătura de sus"14.

Părintele Dumitru Stăniloae afirmă, și el, că glasul lui Dumnezeu către Moise nu a fost un glas perceput de urechea omenească dar în același pasaj lasă deschisă posibilitatea ca el să fi fost totuși un glas real, și totodată accentuând caracterul minunat dar şi foarte apofatic al momentului vederii și contemplării lui Dumnezeu de către Moise. „Desigur glasul nu se auzea cu urechea trupească și cuvintele nu răsunau material. (Sau poate se auzeau și cu urechea trupească și răsunau material pentru că se auzeau mai întâi în suflet într-un mod mai presus de auzul material). Dar Moise auzea sensul cuvintelor în conștiință și simțea întipărindu-i-se în conștiință acest sens cu putere" 15 .

În acest moment al revelaţiei de pe muntele Sinai cuvintele Domnului au fost puse în formă scrisă. „Una dintre primele forme narative este cuprinsă în darea tablelor celor de piatră pe care au fost scrise Cele Zece Porunci: și El le-a dat lui Moise, când El le-a scris de mână și a încetat să vorbească cu el pe Muntele Sinai, cele două Table ale Testamentului, tăblițe de piatră, scrise cu degetul lui Dumnezeu (Ieșire 31, 18), și tăblițele au fost munca lui Dumnezeu, și scrisul era scrisul lui Dumnezeu, gravat pe tăblițe (Ieșire 32, 16)"16.

\footnotetext{
${ }^{14}$ Ibidem, p. 71.

${ }^{15}$ Pr. Prof. Dr. Dumitru Stăniloae, Comentarii la Sf.Grigorie de Nyssa, Despre viața lui Moise sau desăvârșirea prin virtute...., p. 74.

${ }^{16}$ Wayne Grudem, Sistematic Theology An Introduction to Biblical Doctrine, Michigan, Ed. Zonderman, 2000, p.49.
} 


\section{Cunoașterea prin Cuvânt în Noul Testament}

Continuatorul semnificațiilor lui davar în Noul Testament este termenul de logos. Acesta apare cu aceleaşi sensuri multiple precum davar și, mai mult, evoluează concomitent cu revelația, desemnând întocmai cuvintele și Persoana Mântuitorului Hristos surprinse la: „1 Tes. 4, 15, Evangheliile, Fapte 8, 25; 13, 49; 15, 35-36; 16, 32; 19, 10; 1 Tes. 1: 8; 2 Tes. 3,1 "'17.

Sf. Iustin Martirul și Filozoful este cel care insistă că învățătura Scripturii depășește orice altă învățătură omenească: „Deci, cele ale noastre, depășesc orice altă învățătură omenească, prin aceea că noi avem în Hristos întreg Cuvântul, Care S-a arătat pentru noi trup, Cuvânt și suflet. Căci tot ceea ce au grăit și au găsit filozofii și legiuitorii, au fost scoase de ei cu trudă din ceea ce au găsit contemplând doar în parte Cuvântul"18.

Există o compatibilitate între mit și logos, mitul fiind construit pe o bază narativă, întotdeauna credibilă și rațională, ce consolidează coerența și credibilitatea mitului, ,dar în mit nu există o experiență a evenimentului" 19 .

Prin stoici, se face legătura dintre logos și discurs. Este un punct de unitate ce susține lucrarea reală a logosului prin vorbire, și prin care „stoicii formulează ideea că există un logos endiathetos (intern sau interior) și unul extern sau exterior, logos profhorikos"20. Sunt două secvențialități ale lucrării aceluiași Logos, prin care se pot înțelege actele și prezența Logosolui în lume. Logosul endiathetos se tratează

\footnotetext{
${ }^{17}$ Vines, Complete Expository Dictionary of Old and New Testament Words, W. E. Vine, Merrill F. Unger, Whilliam White Jr., 1940, electronic edition, p. 1577. ${ }^{18}$ Sf. Iustin Martirul și Filozoful, Apologia a II-a, PSB, vol. 2, trad. Pr. Prof. T. Bodogae, Pr. Prof. Olimp Căciulă, Pr. Prof. D. Fecioru, București, Ed. EIBMBOR, 1980, p. 84.

${ }^{19}$ Raoul Mourtley, From Word to Silence, The rise and fall of logos, vol.I, Bonn, Ed. Hanstein, 1986, p. 13.
}

${ }^{20}$ Ibidem, p. 13. 


\section{Lucian DABIJA}

prin tăcere, este caracterizat de manifestare discretă, germinatoare, fiind cel care nu este reprezentat decât prin ambiguitate. Raportul său cu logosul profhorikos este asemănător cu raporturile complementare ale metodelor de cunoaştere. Toate diferențierile se reconstruiesc într-o permanentă completare și relaționare.

Așadar, Logosul este inerent lumii. Probabil de aceea, și grecii au ales mai târziu să înlocuiască mitul cu perspectiva creștină asupra Cuvântului lui Dumnezeu. „Așa cum, afirmă Nestle, că din cauza slăbiciunilor graduale ale mitului, se permite Cuvântului să îl înlocuiască, dar trebuie reiterat că, Cuvântul a dat naștere acestei apropieri către mit" 21 .

Evoluția înțelegerii asupra Logosului a adus un real progres cunoașterii universale, fiind posibile trasarea liniilor definitorii pe care gândirea modernă le-a preluat de la filosofii greci. „Parmenide este primul care ne invită «să judecăm cu rațiune» (logos); este cel mai contestat argument care ne-a fost dat..... Este pentru prima dată când sensul și raţiunea contrastează, și nu afirmăm că sensul este decisiv, și că rațiunea singura este de crezut" ${ }^{22}$. Este primul pas către cartezianism.

Sfântul Apostol Ioan, în Prologul celei de-a Patra Evanghelii, înalță perspectivele cunoaşterii universale despre Logos. Încă din primul verset, el afirmă natura divină a Logosului, identificând Logosul cu Dumnezeu (Ioan 1,1). Prin acest verset rezumă toată cunoașterea iudaică și elenistă despre Logos.

Până la versetul al 14-lea, Sf. Ioan reafirmă caracterul apofatic, nedesluşit al creări lumii prin (pros) lucrarea și participarea Logosului, „Întru-El fiind viața și lumina oamenilor” (Ioan 1,4). Ethosul iudaic este exprimat și înțeles prin prisma fiecărui moment revelaţional cuprins în Vechiul Testament și comentat apoi de întreaga Tradiție.

\footnotetext{
${ }^{21}$ Ibidem, p. 15.

${ }^{22}$ Ibidem, p. 19.
} 
Versetul 14 din Prolog reprezintă un punct de referință al întregii înţelegeri asupra Logosului. Sf. Ioan afirmă întruparea Logosului „Şi Cuvântul S-a făcut trup și S-a sălășluit între noi, și am văzut slava Lui, slavă ca Unuia Născut din Tatăl plin de har și de adevăr”, și „face parte din singura idee ce umple Prologul - Cuvântul care a făcut lumea este Fiul lui Dumnezeu, Iisus Hristos, care ne-a dat lumina, și viața, harul și adevărul"²3. Este o dimensiune decisivă prin care Logosul este afirmat în istorie, El intră în istorie, depăşind viziunea iudaică prin care Mesia este așteptat. Ambele perspective, iudaică și greacă, culminează în acest punct al afirmaţiilor Sf. Ioan. Întruparea este evenimentul Cuvântului așteptat de întreaga omenire - formulă ce caracterizează întreaga concepție despre Cuvântul lui Dumnezeu"24. De această dată, Cuvântul nu mai este făcut cunoscut prin mesageri, ci propovăduiește despre Sine, direct, vorbindu-le tuturor. De acum, Logosul nu mai este un principiu abstract, cosmic, ci este persoană în trup, ale cărui fapte și cuvinte le regăsim scrise în Biblie.

\section{Bibliografie}

1. Biblia Sacra Iuxta Vulgatam Versionem, Ed. by R.Weber, B. Ficher, J. Gribomont, H. F. D. Sparks and W. Thiele, Stuttgart, Ed. Deutche Bibelgesellachft, 1993.

2. Biblia, București, Tipografia Cărților Bisericești, 1914.

3. Nestle-Alland, Novum Testamentum Graece, Stuttgart, Deutche Bibelgesellachft, 1993.

4. Septuaginta, volum coordonat de Cristian Bădiliță, Francisca Băltăceanu, Monica Broșteanu, Dan Slușanschi în colaborare cu pr. Ioan-Florin Florescu, vol. 1, Colegiul Noua Europă, București, Ed. Polirom, 2004.

${ }^{23}$ Andre Feuillet, Introduction to the New Testament, New York-Rome-ParisYournai, Ed. Desclee, 1965, p. 617.

${ }^{24}$ Colin Brown, New Testament Theology, Exeter, Devon, Ed. Pater Noster Press, 1978, p.1090. 
5. Hârloianu, Alfred, Dicţionar explicativ român-ebraic de la literele Alef-Lamed, ediţia a-II-a, Bucureşti, Ed. Nemira, 2002.

6. Doob, Katharine, Sakenfeld, The New Interpreters Dictionary of the Bible S-Z, vol. 5, Nashville, Ed. Abington Press, 2009.

7. Van Hoozer, Kevin J., Michigan Dictionary for Theological Interpretation of the Bible, ed., Ed. Baker Academic, 2005.

8. Sf. Augustin, De doctrina christiana, trad. Marian Ciucă, București, Ed. Humanitas, 2002.

9. Foucault, Michel, Cuvintele și lucrurile, trad. Bogdan Ghiu și Mircea Vasilescu, București, Ed. Rao, 2008.

10. Sf. Grigorie de Nyssa, Despre viața lui Moise sau desăvârșirea prin virtute, Scrieri partea I, PSB, vol. 29, Trad. Dumitru Stăniloae și Pr. Ioan Buga, București, Ed. EIBMBOR, 1982.

11. Grudem, Wayne, Sistematic Theology An Introduction to Biblical Doctrine, Michigan, Ed. Zonderman, 2000.

12. Stăniloae, Dumitru, Dumnezeu este Lumina, Ortodoxia, nr. 1, an XXVI, 1974.

13. Sf. Ambrozie al Milanului, Tâlcuiri la Sfânta Scriptură, PSB, vol. 52, București, Ed. EIBMBOR, 2007.

14. Vines, Complete Expository Dictionary of Old and New Testament Words, W. E. Vine, Merrill F. Unger, Whilliam White Jr., 1940, electronic edition.

15. Sf. Iustin Martirul și Filozoful, Apologia a-II-a, PSB, vol. 2, trad. Pr. Prof. T. Bodogae, Pr. Prof. Olimp Căciulă, Pr. Prof. D. Fecioru, București, Ed. EIBMBOR, 1980.

16. Mourtley, Raoul, From Word to Silence, The rise and fall of logos, vol.I, Bonn, Ed. Hanstein, 1986.

17. Hamrick, Wiliam S. and Vand Der Veken, Jan, Nature and Logos A Whiteheadian Key to Merleau Pontiys Fundamental Thought, Albany New York, Ed. State University Press of New York Press, 2011.

18. Feuillet, Andre, Introduction to the New Testament, New YorkRome-Paris-Yournai, Ed. Desclee, 1965.

19. Brown, Colin, New Testament Theology, Exeter, Devon Ed. Pater Noster Press, 1978. 